\title{
Synthesis, characterization and studies on antioxidant and molecular docking of metal complexes of 1-(benzo[d]thiazol-2-yl)thiourea
}

\author{
HARINATH YAPATI $^{\mathrm{a}}$, SUBBA RAO DEVINENI ${ }^{\mathrm{b}}$, SURESH CHIRUMAMILLA $^{\mathrm{a}}$ and \\ SESHAIAH KALLURU ${ }^{\mathrm{a}, *}$ \\ a Inorganic and Analytical Chemistry Division, Sri Venkateswara University, Tirupati 517 502, \\ Andhra Pradesh, India \\ ${ }^{\mathrm{b}}$ Research and Development Centre, Micro Labs Ltd., API Division, Bommasandra-Jigini Link Road, \\ KIADB INDL Area, Bangalore 560 100, Karnataka, India \\ e-mail: seshaiahsvu@gmail.com
}

MS received 24 July 2015; revised 20 October 2015; accepted 21 October 2015

\begin{abstract}
In the present study, a new thiourea derivative bearing benzothiazole ligand, 1-(benzo[d]thiazol-2yl)thiourea (btt) and its ternary metal (Cu(II), $\mathrm{Co}$ (II) and $\mathrm{Ni}(\mathrm{II})$ ) complexes were synthesized. The structural characterization was carried out by micro analysis, IR, ${ }^{1} \mathrm{H}-\mathrm{NMR}$, EPR, UV-Visible spectral analyses, molar conductance and thermal analysis studies. Spectral studies of complexes revealed that the metal complexes have distorted octahedral geometry. Molecular modelling study was performed to evaluate the recognition of target compounds at the $3 \mathrm{MNG}$ binding pocket. The docking results revealed that copper complex selectively binds to the crucial amino acid residues in the active site of $3 \mathrm{MNG}$. The in vitro antioxidant activity of the ligand and its metal complexes was assayed by radical scavenging activity (DPPH, $\mathrm{H}_{2} \mathrm{O}_{2}$ and NO) and ferric reducing antioxidant power (FRAP) methods. The ligand showed moderate antioxidant activity whereas the metal complexes exhibited better antioxidant activity than that of the ligand. The results of the four methods proved that the copper complex is the most potent antioxidant among all the tested compounds.
\end{abstract}

Keywords. Benzo[d]thiazol; thiourea; metal complexes; antioxidant activity; molecular docking.

\section{Introduction}

Thioureas are important functional derivatives possessing good biological activities like antiviral, antibacterial, antifungal, antitubercular, anti-thyroidal, herbicidal and insecticidal. ${ }^{1-4}$ These are also found as precursors or intermediates in the synthesis of a variety of heterocyclic systems such as imidazole-2-thiones, 2imino-1,3-thiazolines, $\mathrm{N}$-4-substituted-benzyl- $N$-tertbutylbenzyl thioureas as vanilloid receptors and antagonists in rat DRG neurons. ${ }^{5}$ Further, nitrogen and sulfur donor atoms in thiourea provide a multitude of bonding possibilities, hence, its derivatives are versatile ligands and are able to coordinate to metal centers either as neutral ligands, mono anions or di-anions and form stable complexes. ${ }^{6}$ They can behave as thiolate-type ligands, since a substituted thiourea bearing at least one hydrogen, $\mathrm{R}^{1} \mathrm{R}^{2} \mathrm{NC}(=\mathrm{S}) \mathrm{NHR}^{3}$ can exist in a tautomeric thiolate form, i.e., $\mathrm{R}^{1} \mathrm{R}^{2} \mathrm{C}(\mathrm{SH})=\mathrm{NR}^{3}$. Metal complexes of thiourea derivatives are bio-active compounds and show wide range of biological activities. ${ }^{7}$

*For correspondence
The thiazoles, containing $\mathrm{N}$ and $\mathrm{S}$ heterocycles, are found in many naturally occurring compounds. ${ }^{8-11}$ Thiazoles are used as neuro protectors ${ }^{12,13}$ and antioxidants. ${ }^{14,15}$ They also form biologically potent metal complexes. ${ }^{16-19}$ Metal complexes of thiazoles recently attracted attention of inorganic, metallo-organic as well as bio-inorganic chemists because of their extensive applications in wide ranging areas from material to biological sciences. ${ }^{20}$

Thioazoles attached with thiourea functional group are used as pharmaceutical agents. ${ }^{21}$ The biological and synthetic significance of thiazole, and thiourea derivatives prompted us to synthesize new molecules: 1-(benzo[d]thiazol-2-yl)thiourea and its (Cu(II), $\mathrm{Co}$ (II) and $\mathrm{Ni}(\mathrm{II})$ ) complexes. Transition metal ions such as $\mathrm{Cu}(\mathrm{II}), \mathrm{Co}(\mathrm{II})$ and $\mathrm{Ni}(\mathrm{II})$ were selected since they enhance biological activity. ${ }^{22,23}$ The synthesized ligand and metal complexes were characterized by elemental analyses, IR, ${ }^{1} \mathrm{H}-\mathrm{NMR}$, ESR, UV-Visible spectra, molar conductance and thermal analysis studies. Further, the in vitro antioxidant activity and molecular modelling study against $3 \mathrm{MNG}$ binding pocket were performed. 


\section{Experimental}

\subsection{Materials and physical measurements}

Analytical grade (AR) chemicals with high purity were purchased from Sigma Aldrich, Spectrochem and S D Fine Chem. and used without further purification. The analysis of CHNS of ligand and metal complexes were carried out on Euro elemental analyzer. IR spectra were recorded on Bruker spectrometer. ${ }^{1} \mathrm{H}$ NMR was recorded on a Bruker Advanced Drx-200 MHz spectrometer with TMS as an internal standard. The melting points of the compounds were determined on Beijing XT-4-100x microscopic melting point apparatus and are uncorrected. TG/DTA curves for the complexes were recorded on Nietzsche thermo balance (model-STA $40 \mathrm{~g}$ ) with $\mathrm{PtVsP}_{\mathrm{t}} 10 \% \mathrm{Rh}$ thermocouple in dynamic air conditions between the room temperature $\left(\sim 20^{\circ} \mathrm{C}\right)$ and $1020^{\circ} \mathrm{C}$ (rate $10 \mathrm{~K} / \mathrm{min}$ ).

\subsection{Preparation of the ligand: 1-(benzo[d]thiazol-2-yl) thiourea}

Aniline (0.1 mole, $9.10 \mathrm{~mL})$ (1) and concentrated hydrochloric acid $(15 \mathrm{~mL})$ were mixed and the solution was warmed for $30 \mathrm{~min}$. A saturated solution of ammonium thiocyanate in water $(5 \mathrm{~g}$ in $10 \mathrm{~mL})$ was added slowly to the above solution. The mixture was boiled until the solution attained the turbidity. This solution was poured in cold water. The precipitate was filtered and re-crystallized from aqueous ethanol to afford pure phenylthiourea (2). The phenylthiourea $(20 \mathrm{mmol}, 3.04 \mathrm{~g})$ in chloroform $(20 \mathrm{~mL})$ was brominated by using bromine solution in chloroform (5\%) till the orange-yellow colour appeared. The slurry was kept overnight at ambient temperature. The obtained precipitate was filtered and washed with chloroform until the color disappeared. The precipitate as hydrobromide was dissolved in rectified spirit $(30 \mathrm{~mL})$ and basified with ammonia solution $(20 \mathrm{~mL})$. The precipitate was filtered, washed with water, dried and recrystallized from ethanol:dichloromethane mixture $(1: 2)$ to get pure benzo[d]thiazole-2-amine (3). The compound (3) was treated with concentrated hydrochloric acid $(20 \mathrm{~mL})$ and warmed for $30 \mathrm{~min}$. A saturated solution of ammonium thiocyanate in water $(5 \mathrm{~g}$ in $10 \mathrm{~mL})$ was added slowly to the above solution. The mixture was boiled until the solution got turbidity. The turbid solution was poured in cold water. The resulting precipitate was filtered and recrystallized from aqueous ethanol (80\%) to obtain pure 1-(benzo[d]thiazol-2-yl)thiourea (4). Yellow solid, Yield: $80 \%$, M.p.: $174^{\circ} \mathrm{C}$, Anal. Calc. for $\mathrm{C}_{8} \mathrm{H}_{7} \mathrm{~N}_{3} \mathrm{~S}_{2}$ : C, 45.91; H, 3.37; N, 20.08; S, 30.64\%.
Found: C, 45.86; H, 3.41; N, 20.05; S, 30.61\%. IR $\left(\mathrm{cm}^{-1}\right) ; 3318(\mathrm{w}), 1565(\mathrm{~m}), 842(\mathrm{~m}), 710$ (s). ${ }^{1} \mathrm{H}-\mathrm{NMR}$ $\left(\mathrm{DMSO}_{6}\right): \delta 2.54(\mathrm{~s}, 1 \mathrm{H}, \mathrm{NH}), 9.30\left(2 \mathrm{H}, \mathrm{s}, \mathrm{NH}_{2}\right)$, 7.20-7.85 (4H, m, Aromatic). ${ }^{13} \mathrm{C}-\mathrm{NMR}$ (DMSO-d6) in $\delta$ (ppm): 144.3, 169.01, 116.31, 123.3, 124.0, 127.2, 127.7, 128.3. Electronic spectra (DMF, $\left.\mathrm{cm}^{-1}\right) ; 47619$, 37735, 43516, 26667.

\subsection{Synthesis of Metal Complexes}

All the three metal complexes (5-7) were prepared by a general procedure. To the hot solution $\left(60^{\circ} \mathrm{C}\right)$ of the appropriate metal chloride $(1 \mathrm{mmol})$ in ethanol and water mixture $(1: 1,25 \mathrm{~mL}), 1$-(benzo[d]thiazol-2-yl) thiourea (4) (0.41 g, $2 \mathrm{mmol})$ was added to the same solvent mixture $(20 \mathrm{~mL})$. The resulting mixture was stirred under reflux for $1-2 \mathrm{~h}$, the precipitate was filtered off, washed twice with a 1:1 ethanol: water mixture.

2.3a $\left[\mathrm{Cu}(\mathrm{btt})_{2} \mathrm{Cl}_{2}\right]$ (5): Green solid, Yield: 83\%, M.p.: $246^{\circ} \mathrm{C}$, Anal(\%). Calcd(\%). for $\mathrm{C}_{16} \mathrm{H}_{12} \mathrm{Cl}_{2} \mathrm{CuN}_{6}$ $\mathrm{S}_{4}$ : C, 34.90, H, 2.23, N, 15.22, S, 23.26, Cu, 11.54, Cl, 12.89. Found: C, 34.88, H, 2.23, N, 15.22, S, 23.26, Cu, 11.54, $\mathrm{Cl}, 12.89 \%$. IR data $\left(\mathrm{KBr}, \mathrm{cm}^{-1}\right) ; 3329(\mathrm{w}), 1584$ (m), 762 (m), 718 (s). ${ }^{1} \mathrm{H}-\mathrm{NMR}$ (DMSO-d6; $\delta 10.23$ $\left(2 \mathrm{H}, \mathrm{s}, \mathrm{NH}_{2}\right), 7.25-7.91(4 \mathrm{H}, \mathrm{m}$, Aromatic). Electronic spectra (DMF, $\left.\mathrm{cm}^{-1}\right) ; 15267,16525,17211,21739$.

2.3b $\left[\mathrm{Co}(\mathrm{btt})_{2} \mathrm{Cl}_{2}\right](\mathbf{6})$ : Reddish-brown solid, Yield: $79 \%$, M.p.: $320^{\circ} \mathrm{C}$, $\mathrm{Anal}(\%)$. Calcd(\%). For $\mathrm{C}_{16} \mathrm{H}_{12} \mathrm{Cl}_{2}$ $\mathrm{CoN}_{6} \mathrm{~S}_{4}: \mathrm{C}, 35.20, \mathrm{H}, 2.25, \mathrm{~N}, 15.36, \mathrm{~S}, 23.45$, Co, 10.81, Cl 13.02. Found: C, 35.17, H, 2.21, N, 15.38, S, 23.47, Co, 10.79, $\mathrm{Cl}, 12.98$. IR data $\left(\mathrm{KBr}, \mathrm{cm}^{-1}\right): 3332$ (w), 1585 (m), 786 (m), 724 (s). ${ }^{1}$ H-NMR (DMSO-d ${ }_{6}$; $\delta 9.07\left(2 \mathrm{H}, \mathrm{s}, \mathrm{NH}_{2}\right), \delta 7.40-7.82(4 \mathrm{H}, \mathrm{m}$, Aromatic). Electronic spectra (DMF, $\left.\mathrm{cm}^{-1}\right) ; 17856,21734$.

2.3c $\left[\mathrm{Ni}(\mathrm{btt})_{2} \mathrm{Cl}_{2}\right](7):$ Pale green solid, Yield: $82 \%$, M.p.: $284^{\circ} \mathrm{C}$, Anal(\%). Calcd(\%). For $\mathrm{C}_{16} \mathrm{H}_{12} \mathrm{Cl}_{2} \mathrm{NiN}_{6}$ $\mathrm{S}_{4}$ : C, 35.22, H, 2.25, N, 15.36, S, 23.45, Ni, 10.81, Cl 13.02. Found: C, 35.19, H, 2.21, N, 15.39, S, 23.48, $\mathrm{Ni}, 10.75, \mathrm{Cl}, 12.98$. IR data $\left(\mathrm{KBr}, \mathrm{cm}^{-1}\right) ; 3326(\mathrm{w})$, 1585 (m), 774 (m), 719 (s). ${ }^{1}$ H-NMR (DMSO-d 6 ; $\delta 9.71$ $\left(2 \mathrm{H}, \mathrm{s}, \mathrm{NH}_{2}\right), \delta$ 7.25-7.91 (4H, m, Aromatic). Electronic spectra $\left(\mathrm{DMF}, \mathrm{cm}^{-1}\right) ; 24271,15360,9576$.

\subsection{Molecular docking}

Molecular modeling studies were performed using Molecular Operating Environment (MOE) version 
2008.10 for the synthesized compounds, which exhibited promising and lower antioxidant activity in vitro to find the preferred binding conformations in the receptor. ${ }^{24}$ Three dimensional structures of the ligand and metal complexes were outlined by Hyper Chem software which is a refined molecular modeling environment that uniting with quantum chemical calculations, molecular mechanics and dynamics. ${ }^{25}$ The starting coordinates of the human antioxidant enzyme in complex ${ }^{26,27}$ with the competitive inhibitor DTT (PDB: 3MNG) were taken from the Protein Data Bank (http:// www.rcsb.org/pdb). The docking study was carried out by the protein loaded in MOE and the errors of the protein were corrected by the structure preparation processes in MOE. After the corrections, the ligand molecules were removed and the polar hydrogen atoms were added to the isolated target with their standard geometry. Energy minimization (MMFF94x, gradient: 0.05) was performed and the lowest energy conformers were selected as the global minimal for modeling study. The active site was identified from PDB Sum as well as correlated with 'Site Finder' module of MOE to define the docking site for the ligands. The standard protocol implemented in MOE 2008.10 was followed for docking procedure. The selected ligands were docked against the lead competitive inhibitor ligand DTT at the crystal enzyme structure of the target protein and the best energy conformations of receptorligand were studied, and the energy of binding was calculated as the difference between the energy of the complex and the individual energies of enzyme and ligand.

\subsection{Antioxidant activity}

2.5a 1,1-Diphenyl-2-picryl-hydrazyl (DPPH) assay: DPPH has been widely used to evaluate the free radical scavenging capacity of different antioxidants. The radical in the DPPH has a strong absorption maximum at $517 \mathrm{~nm}$ and the absorbance of DPPH decreases, when the radical reacts with the antioxidant. All the tested samples in various concentrations $(50,75$ and $100 \mu \mathrm{g} / \mathrm{mL})$ were prepared in $\mathrm{MeOH}$ and the homogeneous solutions were achieved by stirring. Aliquot of test sample ( $1 \mathrm{~mL}$ ) was added to $4 \mathrm{~mL}$ of $0.004 \%(\mathrm{w} / \mathrm{v})$ methanol solution of DPPH and the reaction mixture was vortexed for $1 \mathrm{~min}$ and kept at room temperature for $30 \mathrm{~min}$ in the dark to complete the reaction. The absorbance was read against blank at $517 \mathrm{~nm}$. The synthetic antioxidant BHT was used as positive control. The ability of the tested samples at tested concentration to scavenge DPPH radicals was calculated using equation 1 . The experiment was carried out in triplicate and the average values calculated.

$$
\begin{array}{r}
\% \text { of scavenging }=\left[1-\left(\mathrm{A}_{\text {sample }}-\mathrm{A}_{\text {sample-blank }}\right)\right. \\
\left./ \mathrm{A}_{\text {control }}\right] \times 100
\end{array}
$$

Here, $\mathrm{A}_{\text {control }}$ is the absorbance of the control (DPPH solution without the test compound) and $\mathrm{A}_{\text {sample }}$ is the absorbance of the test sample (DPPH solution with the test compound) and $\mathrm{A}_{\text {sample-blank }}$ is the absorbance of the sample solution (the test compound solution without $\mathrm{DPPH})$.

2.5b Hydrogen peroxide $\left(\mathrm{H}_{2} \mathrm{O}_{2}\right)$ scavenging activity: The hydroxyl radical $\left(\mathrm{OH}^{\bullet}\right)$ in aqueous media was generated through the Fenton reaction. The solutions of the test compounds were prepared in DMF. The reaction mixture containing $2.5 \mathrm{~mL}$ of $0.15 \mathrm{M}$ phosphate buffer $(\mathrm{pH}=7.4), 0.5 \mathrm{~mL}$ of $114 \mu \mathrm{M}$ safranin, $1 \mathrm{~mL}$ of $945 \mu \mathrm{M}$ EDTA-Fe(II), $1 \mathrm{~mL}$ of $3 \% \mathrm{H}_{2} \mathrm{O}_{2}$ and $30 \mu \mathrm{L}$ of the test compound solution were prepared. The reaction mixture without the test compound was used as the control. The reaction mixtures were incubated at $37^{\circ} \mathrm{C}$ for $60 \mathrm{~min}$ on a water bath. Absorbances $\left(\mathrm{A}_{\mathrm{i}}, \mathrm{A}_{0}, \mathrm{~A}_{\mathrm{c}}\right)$ at $520 \mathrm{~nm}$ were measured. The scavenging ratio for $\mathrm{OH}^{\bullet}$ was calculated from equation 2 .

$$
\text { Scavenging ratio }(\%)=\frac{A_{i}-A_{0}}{A_{c}-A_{0}} \times 100
$$

Where, $A_{i}$ is the absorbance in the presence of the tested compound, $\mathrm{A}_{0}$ is the absorbance in the absence of the tested compound and $\mathrm{A}_{\mathrm{c}}$ is the absorbance in the absence of the tested compound, EDTA-Fe(II) and $\mathrm{H}_{2} \mathrm{O}_{2}$.

2.5c Nitric oxide (NO) scavenging activity: Nitric oxide scavenging activity of the tested samples was measured using a slightly modified protocol of Green et al. and Marcocci et al. ${ }^{28,29}$ All the tested samples in various concentrations (50, 75 and $100 \mu \mathrm{g} / \mathrm{mL})$ were prepared in DMF and homogeneous solutions were achieved by stirring. Nitric oxide radicals (NO) were generated from $1 \mathrm{~mL}$ of sodium nitroprusside $(10 \mathrm{mM})$ and $1.5 \mathrm{~mL}$ of phosphate buffer saline $(0.2 \mathrm{M}, \mathrm{pH} 7.4)$ were added to the test compounds and incubated for $150 \mathrm{~min}$ at $25^{\circ} \mathrm{C}$. The reaction mixture of the above samples $(1 \mathrm{~mL}$ each) was treated with $1 \mathrm{~mL}$ of Griess reagent ( $1 \%$ sulfanilamide, $2 \% \mathrm{H}_{3} \mathrm{PO}_{4}$ and $0.1 \%$ naphthylene diamine dihydrochloride). The absorbance was measured at $546 \mathrm{~nm}$. Butylated hydroxy toluene (BHT) was used as a positive control. The ability to scavenge the NO radicals was calculated by equation 3 .

$$
\% \text { of Scavenging }=\frac{A_{\text {control }}-A_{\text {sample }}}{\mathrm{A}_{\text {control }}} \times 100
$$


$2.5 \mathrm{~d}$ Ferric reducing antioxidant power (FRAP): The reducing power of synthesized compounds was determined according to the method of Oyaizu. ${ }^{30}$ Various concentrations of the tested compounds, 50, 75 and $100 \mathrm{mM}$ were mixed with $2.5 \mathrm{~mL}$ of phosphate buffer (0.2 M, pH 6.6) and $2.5 \mathrm{~mL}$ of $1 \%$ potassium ferric cyanide and incubated at $50^{\circ} \mathrm{C}$ for $20 \mathrm{~min} .2 .5 \mathrm{~mL}$ of $10 \%$ trichloro acetic acid was added to this mixture and centrifuged at $3000 \mathrm{rpm}$ for $20 \mathrm{~min}$. The upper layer $(2.5 \mathrm{~mL})$ was mixed with $2.5 \mathrm{~mL}$ of deionized water and $0.5 \mathrm{~mL}$ of $0.1 \%$ ferric chloride and the absorbance was measured at $700 \mathrm{~nm}$ using a spectrophotometer (Shimadzu 160A). Increase in the absorbance of the reaction mixture indicates higher reducing power. The experiment was repeated in triplicate and mean reducing power values are summarized in Figure S11 (in Supplementary Information, SI). BHT was used as standard and compared with the reducing power of the synthesized complexes.

\section{Results and Discussion}

Keeping in mind the biological importance of the thiourea derivatives bearing heterocyclic scaffold and metal complexes, the ligand, 1-(benzo[d]thiazol-2yl)thiourea (4) was synthesized from the aniline (1) as depicted in scheme 1. All the synthesized intermediates and final product were recrystallized from methanol and used for further study. Later, the desired metal complexes, copper(II), cobalt(II) and nickel(II) were prepared (scheme 2). Analytical data indicated the formation of 1:2 metal complexes of ligands with $\mathrm{Co}(\mathrm{II})$, $\mathrm{Cu}(\mathrm{II})$ and $\mathrm{Ni}(\mathrm{II})$ metal ions. The molar conductance values of the complexes (measured in $10^{-3} \mathrm{M}$ DMF) are in the range of $15-18 \Omega^{-1} \mathrm{~cm}^{2} \mathrm{~mol}^{-1}$ indicating the non-electrolytic nature of the complexs. Solubility of

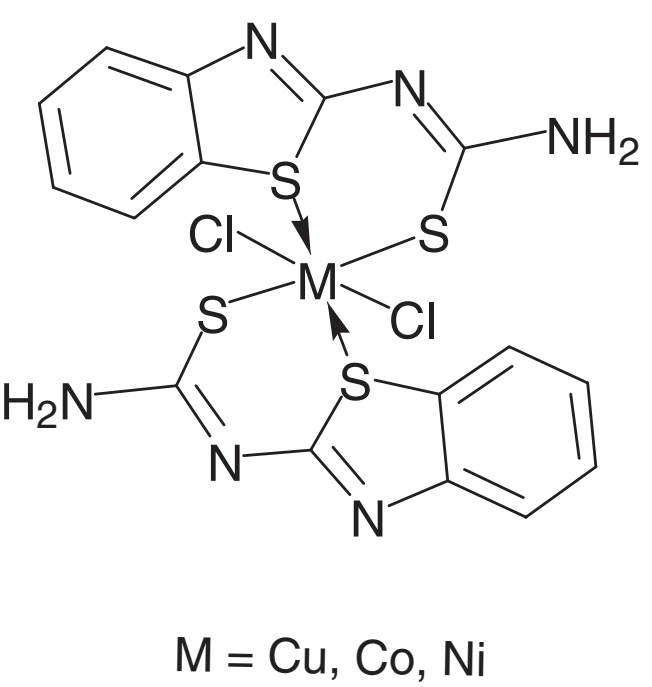

Scheme 2. Proposed structure for metal complexes.

metal complexes is low in water, ethanol, chloroform, acetone and most organic solvents, but have solubility in DMSO, DMF and decompose at higher temperature.

\subsection{IR Spectral Analysis}

The FT-IR spectra of ligand and its metal complexes are shown in figure S1. The bands at 1517 and $751 \mathrm{~cm}^{-1}$ due to thioamide stretching and bending vibrations, respectively, of the free ligand are shifted to lower values indicating coordination of thiolate sulphur to the metal ions (table S1). This negative shift of $v(\mathrm{C}=\mathrm{S})$ in the complexes has already been indicated by Campbell. ${ }^{31}$ In the spectra of all the complexes, a new strong band is found in the range of $1612-1649 \mathrm{~cm}^{-1}$, which may be due to the newly formed $v(\mathrm{C}=\mathrm{N})$ bond as a result of enolization. A strong band observed at $751 \mathrm{~cm}^{-1}$ is attributed to $v(\mathrm{C}-\mathrm{S}-\mathrm{C})$ of thiazole ring.

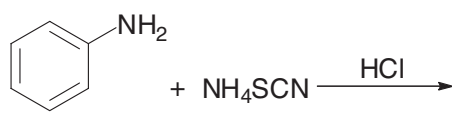

(1)<smiles>NC(=S)Nc1ccccc1</smiles>

(2)

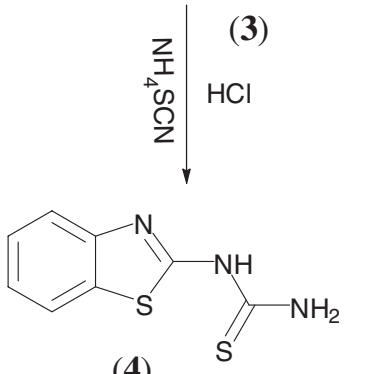

(4)

1-(benzo[d] thiazol-2-yl)thiourea

Scheme 1. Synthetic route for ligand. 
Complexation of the ligand with metals leads to shift in the band to lower frequency. This is probably due to the coordination properties of the ligand and suggesting the involvement of sulfur atoms in the bonding with the metal ions. ${ }^{32}$ The bands near $435-450 \mathrm{~cm}^{-1}$ are ascribed to $v(\mathrm{M}-\mathrm{S}){ }^{33}$ This presents a good evidence for the participation of thiazole and thiourea sulfur atoms in complex formation.

\subsection{Nuclear magnetic resonance spectroscopy}

The formation of ligand was supported by the ${ }^{1} \mathrm{H}$ NMR spectrum, by the appearance of a sharp singlet at $2.54 \mathrm{ppm}$, corresponding to the $\mathrm{N}(2) \mathrm{H}$ proton figure S2). The ${ }^{1} \mathrm{H}-\mathrm{NMR}$ spectra of the complexes when compared with the parent ligand did not show the signal for $\mathrm{N}(2) \mathrm{H}$ at $2.54 \mathrm{ppm}$ indicating that the ligand is coordinated to the metal ions in all the complexes in the thiolate form. The multisignals within the range of $7.20-7.85 \mathrm{ppm}$ are assigned to the aromatic protons of benzothiazole ring. These signals are shifted towards low field in the metal complexes. A singlet for two protons at $\delta 9.30$ is assigned to $\mathrm{NH}_{2}$ protons and shifted towards up field in the complexes. This information suggests the adjustment of electronic current upon coordination of $>\mathrm{C}=\mathrm{S}$ group to the metal ion.

\subsection{Electron paramagnetic resonance spectrum of the $\mathrm{Cu}(\mathrm{II})$ complex}

The X-band EPR spectrum of $\mathrm{Cu}$ (II) complex was recorded at room temperature (figure S3). The $\mathrm{g}_{\text {iso }}$ values and the geometric parameter $\mathrm{G}$, i.e. the measurement of exchange interaction between the copper centers were evaluated by using equations 4 and 5:

$$
\begin{gathered}
\mathrm{g}_{\text {iso }}=\frac{\mathrm{g}_{\|}+g_{\perp}}{3} \\
\mathrm{G}=\frac{\mathrm{g}_{\|}-2.0023}{\mathrm{~g}_{\perp}-2.0023}
\end{gathered}
$$

The evaluated value of $\mathrm{g}$ tensor parameters shows the order as $\mathrm{g}_{\|}>\mathrm{g}_{\perp}>2.0023$ which reveals that $\mathrm{d}_{\mathrm{x}-\mathrm{y}}^{2}{ }^{2}$ is the ground state $^{34}$ and also indicates that the unpaired electron is localized in $\mathrm{d}_{\mathrm{x}-\mathrm{y}}^{2}{ }^{2}$ orbital of the $\mathrm{Cu}$ (II) ion. The tetragonal structure is thus confirmed for the complexes. The complexes in the present study showed the value of $\mathrm{G}<4(\mathrm{G}=2.1383)$ which indicated the effective interaction between the copper centers and the ligand. ${ }^{35}$

\subsection{Electronic spectrum of the 1-(benzo[d]thiazol-2-} yl)thiourea and its complexes

Electronic spectral data of the ligand and its metal complexes are shown in table S2. The electronic spectrum of the ligand exhibited absorption bands at $47,619 \mathrm{~cm}^{-1}$ and $37,735 \mathrm{~cm}^{-1}$ corresponding to $\pi-\pi *$ transitions of the benzenoid system of benzothiazole moiety. ${ }^{36}$ The absorption band at $43,516 \mathrm{~cm}^{-1}$ is attributed to the $\pi$ $\pi *$ transitions of the thiazole moiety. ${ }^{37}$ The broad band at $26,667 \mathrm{~cm}^{-1}$ is due to the transition within the molecule, essentially an intra molecular charge transfer interaction. The electronic absorption spectrum of $\mathrm{Cu}$ (II) complex exhibited three broad, low intensity bands centered at $15,267 \mathrm{~cm}^{-1}, 16525 \mathrm{~cm}^{-1}$ and $17,211 \mathrm{~cm}^{-1}$. These bands might reasonably be assigned to $\mathrm{Cu}$ (II) $\mathrm{d}-\mathrm{d}$ transitions, ${ }^{2} \mathrm{~B}_{1 \mathrm{~g}} \rightarrow{ }^{2} \mathrm{~A}_{1 \mathrm{~g}}\left(\mathrm{~d}_{\mathrm{x}-\mathrm{y}}{ }^{2}-\mathrm{d}_{\mathrm{z}}{ }^{2}\right),{ }^{2} \mathrm{~B}_{1 \mathrm{~g}} \rightarrow{ }^{2} \mathrm{~B}_{2 \mathrm{~g}}$ $\left(\mathrm{d}_{\mathrm{x}-\mathrm{y}}^{2}-\mathrm{d}_{\mathrm{xy}}\right)$ and ${ }^{2} \mathrm{~B}_{1 \mathrm{~g}} \rightarrow{ }^{2} \mathrm{Eg}\left(\mathrm{d}_{\mathrm{x}-\mathrm{y}}^{2}-\mathrm{d}_{\mathrm{xz}}, \mathrm{d}_{\mathrm{yz}}\right)$ respectively. These $\mathrm{d}-\mathrm{d}$ transitions are normally close in energy. These transitions are due to the ${ }^{2} \mathrm{Eg}$ and ${ }^{2} \mathrm{~T}_{2 \mathrm{~g}}$ states of the octahedral $\mathrm{Cu}$ (II) ion (d9) split under the influence of the asymmetric filling causing the tetragonal distortion. A shoulder band observed at $21,739 \mathrm{~cm}^{-1}$ is due to ligand-metal charge transfer (LMCT). The electronic spectrum of Ni(II) complex displayed three broad bands at $24,271 \mathrm{~cm}^{-1}$ (v1), $15,360 \mathrm{~cm}^{-1}$ (v2) and $9576 \mathrm{~cm}^{-1}$ (v3) which are assigned to the spin-allowed transitions from the ground state ${ }^{3} \mathrm{~A}_{2 \mathrm{~g}}(\mathrm{~F}) \rightarrow{ }^{3} \mathrm{~T}_{1 \mathrm{~g}}(\mathrm{P}),{ }^{3} \mathrm{~A}_{2 \mathrm{~g}}(\mathrm{~F}) \rightarrow{ }^{3} \mathrm{~T}_{1 \mathrm{~g}}(\mathrm{~F})$ and ${ }^{3} \mathrm{~A}_{2 \mathrm{~g}}(\mathrm{~F}) \rightarrow{ }^{3} \mathrm{~T}_{2 \mathrm{~g}}(\mathrm{~F})$ states, respectively. The positions of bands indicated that the Ni(II) complex has six coordinated tetragonal geometry. The electronic spectrum of $\mathrm{Co}$ (II) complex showed two spin-allowed transitions at 17856 and $21734 \mathrm{~cm}^{-1}$ which are assignable to ${ }^{4} \mathrm{~T}_{1 \mathrm{~g}}(\mathrm{~F}) \rightarrow{ }^{4} \mathrm{~A}_{2 \mathrm{~g}}(\mathrm{~F})$ and ${ }^{4} \mathrm{~T}_{1 \mathrm{~g}}(\mathrm{~F}) \rightarrow{ }^{4} \mathrm{~T}_{1 \mathrm{~g}}(\mathrm{P})$ transitions respectively. The positions of bands indicated that the $\mathrm{Co}(\mathrm{II})$ complex has six coordinated tetragonal geometry.

\subsection{Thermal analysis of the metal complexes}

In the present investigation, the thermo gravimetry analysis (TG-DTA) of the complexes was carried out in the temperature range of $20-1020^{\circ} \mathrm{C}$ with a sample heating rate $10^{\circ} \mathrm{C} / \mathrm{min}$ in a static nitrogen atmosphere. During the heating, the complexes have undergone a series of thermal changes associated with a weight loss in the samples. The TGA curves of the complexes (figures S4-S6) show three stages of decomposition within the temperature range of $160-770^{\circ} \mathrm{C}$. The first stage of decomposition is observed at $170^{\circ} \mathrm{C}$ to $320^{\circ} \mathrm{C}$ which corresponds to the loss of $\mathrm{HCl}$. This process is accomplished by exothermic peaks observed 
at $270-280^{\circ} \mathrm{C}$. Second stage occurred within the temperature range of $280-620^{\circ} \mathrm{C}$. This stage involves the loss of thiourea moiety. This degradation is accomplished by exo-effects with maxima $370-390^{\circ} \mathrm{C}$. Third stage of decomposition is observed in the temperature range of $400-770^{\circ} \mathrm{C}$. For cobalt complex, fourth stage is observed in between 760 to $870^{\circ} \mathrm{C}$. This process is accompanied by an endo-effect observed at $870^{\circ} \mathrm{C}$. Above this temperature, no weight change is observed, leaving the metal oxide as the final residue.

\subsection{Molecular docking studies}

The antioxidant assay of the synthesized ligand and its metal complexes has revealed that the copper complex exhibited more antioxidant activity, almost equal to the standard, BHT. In order to interpret the binding mode of the compounds in comparison to the competitive antioxidant inhibitor, 1,2-dithiane-4,5-diol (DTT), ${ }^{26}$ the molecular modeling study was conducted for these compounds at the human antioxidant enzyme (3MNG) pocket. The starting coordinate of the human antioxidant enzyme in complex ${ }^{27}$ with the competitive inhibitor DTT (PDB: $3 \mathrm{MNG}$ ) was obtained from the Protein Data Bank (http://www.rcsb.org/pdb). The $3 \mathrm{MNG}$ pocket was loaded into Molecular Operating Environment MOE version $2008.10^{24}$ with high resolution of $2.70 \AA$ and a library was constructed for these selected molecules with receptor. The active site was identified from PDB Sum and recognized the residues, Gly 46, Gln 133, Asn 24, Val 94, Glu 16, Arg 86 to be interacting with DNA as well as correlated with 'Site Finder' module of MOE to define the docking site for the ligands. Hydrophobic and hydrophilic spheres are used to identify the interactive positions which will be the potential ligand binding sites in each possible position.

The binding recognition profile of these synthesized molecules was attained by performing the docking simulation at $3 \mathrm{MNG}$ pocket. The most common $\mathrm{H}$-interactions in the docked structures, bond lengths, bond angles and binding energies are shown in table 1 . In the docked conformers, all the compounds were showing best bonding energies in the order of $\mathbf{5}$ $(-97.4802 \mathrm{kcal} / \mathrm{mol})>\mathbf{4}(-30.3237)>7(-25.7574)$ $>\mathbf{6}(-20.5211)>$ DTT $(-12.3869)$. Interestingly, it was observed that the active molecules, even the least active molecule $\mathbf{6}$, showed better score than antioxidant competitive inhibitor, DTT.

The competitive antioxidant inhibitor, DTT (Figure S7a) formed two bifurcated H-bonds with the key amino acid residues, Gly 47 and Cys 47; the latter is an essential residue for binding and biological activity.
Besides, one more H-bond was formed with the Thr $44 .{ }^{38}$ The docked conformer of ligand (figure S7b) showed no hydrogen bonds among active site residues of 3MNG protein, but it has hydrophobic and electrostatic interactions among ligand and active site residues of $3 \mathrm{MNG}$. The molecular docking of the copper complex (figure S7c) indicated that it forms one stable hydrogen bonding with a bond length $2.76 \AA$ from $\mathrm{CN}$ of copper complex with the $\mathrm{CN}$ group of the key pocket residue of Gly 46. Nickel complex was found to be forming two hydrogen bondings (figure S7d) with bond of lengths 2.89 and $2.57 \AA$ from - CN of the complex with the $-\mathrm{CO}$ and $-\mathrm{CN}$ group of the key pocket residue of Asn24. Cobalt complex showed two hydrogen bonds with bond lengths of 2.73 and $2.41 \AA$ from $-\mathrm{NC}$ of the complex with -CO groups of Glu16 and Val94 (figure 1). Finally, the molecular docking studies for the selected compounds revealed that the synthesized compounds are antioxidant competitive inhibitors in comparison to antioxidant inhibitor, DTT at $3 \mathrm{MNG}$ binding pocket.

\subsection{Antioxidant activity of ligand and complexes}

In vitro antioxidant activity of 1-(benzo[d]thiazol-2yl)thiourea and its metal ( $\mathrm{Cu}(\mathrm{II}), \mathrm{Ni}$ (II) and $\mathrm{Co}(\mathrm{II})$ ) complexes was evaluated by using radical scavenging methods, DPPH, $\mathrm{H}_{2} \mathrm{O}_{2}$, NO and reducing power method (FRAP). The antioxidant property of the tested samples was evaluated at different concentrations (50, 75 and $100 \mu \mathrm{g} / \mathrm{mL}$ ) and butylated hydroxyl toluene (BHT) was used as a standard for the comparison of the activity.

3.7a DPPH radical scavenging activity: DPPH radical scavenging activity (RSA) evaluation is a standard assay in antioxidant activity studies. A freshly prepared DPPH solution exhibits a deep purple colour with an absorption maximum at $517 \mathrm{~nm}$ due to DPPH free radical. This purple colour generally fades/disappears when an antioxidant is present in the medium. More potent antioxidants are able to reduce the absorbance rapidly.

DPPH radical scavenging activity data (figure S8) of the synthesized ligand and metal complexes states that all the compounds showed potency, high to moderate activity. The metal complexes exhibited more radical scavenging activity than that of the ligand. $\mathrm{Cu}$ (II) metal complex exhibited potent antioxidant activity almost close to the standard, BHT and Co(II) complex showed lower antioxidant activity, and $\mathrm{Ni}(\mathrm{II})$ complex and the ligand showed moderate activity. 
Table 1. Molecular docking parameter of ligand and its metal complexes.
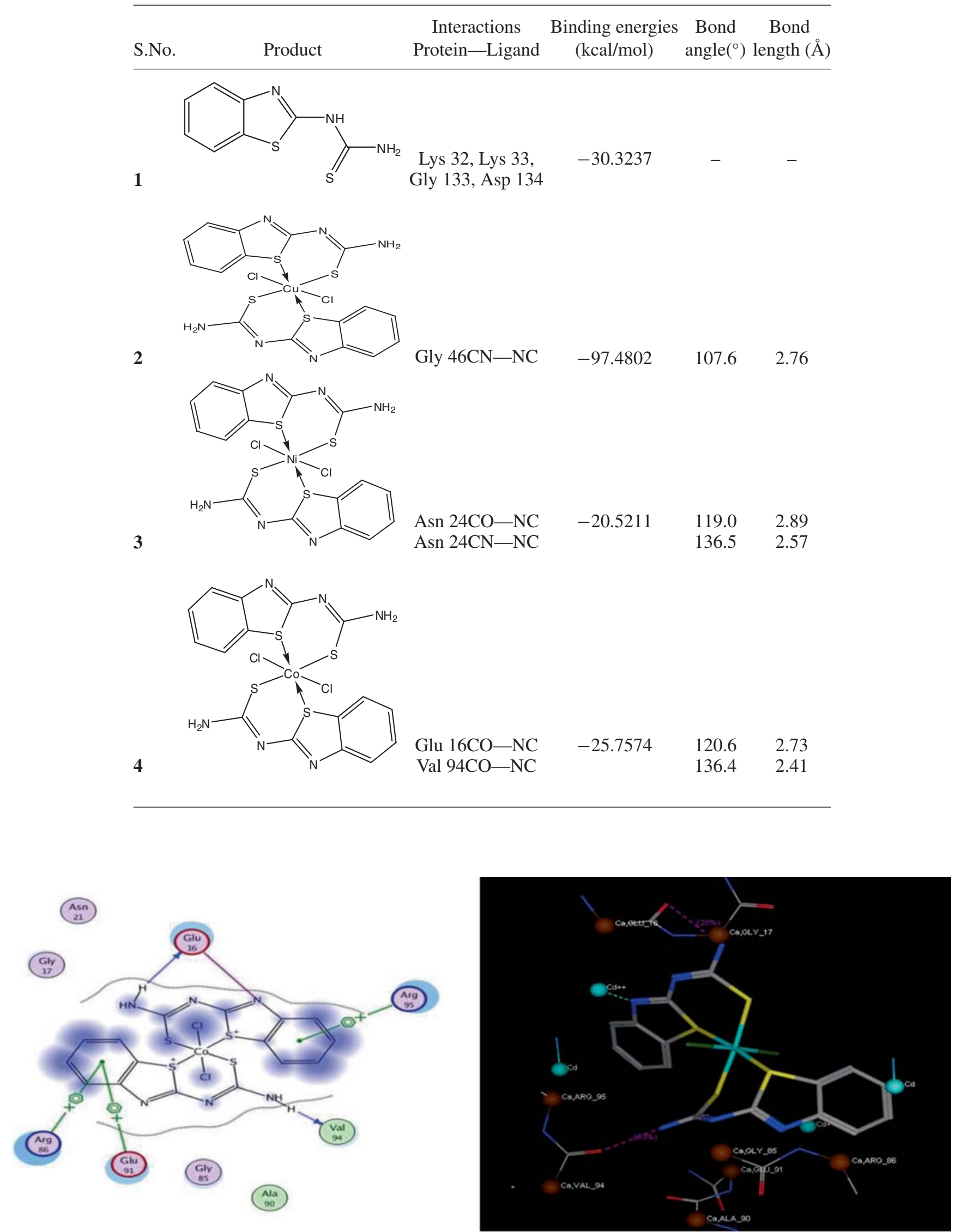

Figure 1. Interaction mode of the cobalt complex docked and minimized in the 3MNG binding pocket. 
3.7b Hydrogen peroxide scavenging activity: Hydrogen peroxide is formed in vivo by many oxidizing enzymes such as superoxide dismutase in biological systems. It can cross membranes and may slowly oxidize a number of compounds. ${ }^{39}$ It is used in the respiratory burst of activated phagocytes. It is known that $\mathrm{H}_{2} \mathrm{O}_{2}$ is toxic and induces cell death. Hydrogen peroxide can attack many cellular energy producing systems. The ability of 1-(benzo[d]thiazol-2-yl)thiourea (btt) and its metal complexes to scavenge hydrogen peroxide at different concentrations was studied and the results (figure S9) were compared with the standard. The results showed that the free ligand and its metal complexes exhibited an effective hydrogen peroxide scavenging activity.

3.7c Nitric Oxide (NO) Scavenging Activity: NO may divert $\mathrm{O}_{2}^{-}$mediated toxic reactions to other oxidative and less damaging, pathways, thus protecting $\mathrm{O}_{2}^{--}$sensitive target molecules. Nitric oxide undergoes a facile radical-radical reaction with $\mathrm{O}_{2}{ }^{--}$, to yield $\mathrm{ONOO}^{-}$, a reaction that is three times faster than the SOD-catalyzed dismutation of $\mathrm{O}_{2}^{--}$. This diversion of $\mathrm{O}_{2}^{--}$through $\mathrm{ONOO}^{-}$oxidation and decomposition pathways would also limit $\mathrm{H}_{2} \mathrm{O}_{2}$ accumulation and subsequent reactions of $\mathrm{H}_{2} \mathrm{O}_{2}$, by decreasing the amount of $\mathrm{O}_{2}^{--}$available for spontaneous or SOD-catalyzed dismutation. We find that the inhibitory effect of the compounds tested on $\mathrm{NO}^{\bullet}$ is concentration-dependent and suppression ratio increases with increasing sample concentrations (figure S10). The copper(II) complex is the most effective among all the complexes.

\section{$3.7 \mathrm{~d}$ Ferric reducing antioxidant power (FRAP):} Figure S11 shows the reducing power of 1-(benzo[d] thiazol-2-yl)thiourea (btt) and its metal complexes. In this assay, the yellow colour of the test solution changes to various shades of green and blue depending upon the reducing power of each compound. The presence of reducers (i.e., antioxidants) causes the reaction of $\mathrm{Fe}^{3+} /$ ferricyanide complex to the ferrous form giving, after addition of trichloro acetic acid and ferric chloride, the Perl's Prussion blue that can be monitored at $700 \mathrm{~nm}$. The reducing power of the standard (BHT) at various concentrations showed higher absorbance value compared to that of the new compounds. The reducing power of the new complexes solutions increased with increase in concentration. Metal complexes showed much better activity than the ligand. All the three complexes showed moderate to high activity which are slightly less than that of the standard: $\mathrm{BHT}>\mathrm{Cu}>\mathrm{Ni}>\mathrm{Co}>$ Ligand.

\section{Conclusions}

The ligand, 1-(benzo[ $d]$ thiazol-2-yl)thiourea (btt) and its metal(II) complexes ( $\mathrm{Cu}$, Co and $\mathrm{Ni}$ ) have been synthesized and characterized by spectral and analytical data. The spectral data showed that the thiourea derivative exists as bidendate ligand by bonding to the metal ions through the deprotonated thiol group and thiazole sulphur. The analytical data showed the presence of one metal ion per two ligand molecules and suggest a mononuclear structure for the complexes. The correlation of the experimental data allows assigning a tetragonal geometry to all the three synthesized complexes. Biological activity studies revealed that the antioxidant activity of the ligand was found to be enhanced on complexation with metal ions. Among the studied complexes, copper complex exhibited high antioxidant activity. Finally, the molecular docking studies of the synthesized compounds were carried out. Molecular docking studies revealed that all the synthesized compounds have relatively less binding energy as compared to the standard drug and may be considered as a good antioxidant agents. Hence this study has widened the scope of developing this type of metal based drugs as promising antioxidant agents.

\section{Supplementary Information}

Figures $\mathrm{S} 1$ to $\mathrm{S} 11$, and tables $\mathrm{S} 1$ and $\mathrm{S} 2$ are provided in the supplementary information. Supplementary Information is available at www.ias.ac.in/chemsci.

\section{Acknowledgements}

The authors wish to thank the CSIR, Government of India (Project 02(0136)/ 13/ EMR-II) for their generous support.

\section{References}

1. Abdullah B H and Salh Y M 2010 Orient. J. Chem. 26 763

2. Stefanska J, Szulczyk D, Koziol A E, Miroslaw B, Kedzierska E, Fidecka S, Busonera B, Sanna G, Giliberti G, Colla P L and Struga M 2012 Eur. J. Med. Chem. 55205

3. Xu Y, Hua W, Liu X and Zhu D 2004 Chin. J. Org. Chem. 241217

4. Yonova P A and Stoilkova G M 2005 J. Plant Growth Regul. 23280

5. Park H, Choi J, Choi S, Park M, Lee J, Suh Y, Cho H, Oh U, Lee J, Kang S U, Lee J, Kim H D, Park Y H, Jeong Y S, Choi J K and Jew S 2004 Bioorg. Med. Chem. Lett. 14787

6. Henderson W, Nicholson B K and Rickard C E F 2001 Inorg. Chim. Acta 320101 
7. Ke S Y and Xue S J 2006 Arkivoc 1063

8. Gunawardana G P, Koehn F E, Lee A Y, Clardy J, He H Y and Faulkner J D 1992 J. Org. Chem. 571523

9. Pettit G R, Kamano Y, Herald C L, Tuinman A A, Boettner F E, Kizu H, Schmidt J M, Baczynskyj L, Tomer K B and Bontems R J 1987 J. Am. Chem. Soc. 1096883

10. Davidson B S 1993 Chem. Rev. 931771

11. Fusetani N and Matsunaga S 1993 Chem. Rev. 931793

12. Ramalingan C, Balasubramanian S, Kabilan S and Vasudevan M 2004 Eur. J. Med. Chem. 39527

13. Zitouni G T, Demirayak S, Ozdemir A, Kaplancikli Z A and Yildiz M T 2003 Eur. J. Med. Chem. 39267

14. Karatepe M and Karatas F 2006 Cell Biochem. Funct. 24547

15. Jaishree V, Ramdas N, Sachin J and Ramesh B $2012 \mathrm{~J}$. Saudi Chem. Soc. 16371

16. Van Beusichem M and Farrell N 1992 Inorg. Chem. 31 634

17. Yu H, Shao L and Fang J 2007 J. Organomet. Chem. 692 991

18. Matczak-Jon E, Kowalik-Jankowska T, Slepkura K, Kafarski P and Rajewska A 2010 Dalton Trans. 391207

19. Neelakantan M A, Mariappan S S, Dharmaraja J, Jeyakumar T and Muthukumaran K 2008 Spectrochim. Acta A 71628

20. Siddiqi Z A, Khalid M, Kumar S, Shahid M and Noor S 2010 Eur. J. Med. Chem. 45264

21. Saeed S, Rashid N, Jones P G, Hussain R and Bhatti M H 2010 Cent. Eur. J. Chem. 8550

22. Ajibade P A and Zulu N H 2011 Int. J. Mol. Sci. 127186

23. AL-Obaidi O H S and Al-Hiti A R H 2012 Am. Chem. Sci. J. 221
24. Balakin K V, Ivanenkov Y A, Skorenko A V, Nikolsky Y V, Savchuk N P and Ivashchenko A A 2004 J. Biomol. Screening 922

25. Dastmalchi S, Hamzeh-Mivehroud M, Ghafourian T and Hamzeiy H 2008 J. Mol. Graphics Modell. 26834

26. Hall A, Parsonage D, Poole L B and Karplus P A 2010 J. Mol. Biol. 10194

27. Bayoumi W A, Elsayed M A, Baraka $\mathrm{H} N$ and Abou-zeid L 2012 Arch. Pharm. Chem. Life Sci. 345 902

28. Green L C, Wagner D A, Glogowski J, Skipper P L and Wishnok J K S R 1982 Anal. Biochem. 126131

29. Marcocci L, Maguire J J, Droy-Lefaix M T and Packer L 1994 Biochem. Biophys. Res. Commun. 201748

30. Kumar H V and Naik N 2010 Eur. J. Med. Chem. 452

31. Campbell M J M 1975 Coord. Chem. Rev. 15279

32. Boca M, Izakovic M, Kickelbick G, Valko M, Renz F, Fuess H and Matuzsna K 2005 Polyhedron 24 1913

33. Mohamed G G, Omar M M and Hindy A M M 2005 Spectrochim. Acta A 621140

34. Searl J W, Smith R C and Wayard S J 1959 Proc. Phys. Soc. 74491

35. Hathaway B J and Billing D E 1970 Coord. Chem. Rev. 5143

36. Etaiw S E, Farag R S, El-Atrash A M and Ibrahim A M A 1992 Spectrochim. Acta A 481025

37. Ibrahim A M A and Etaiw S E H 1997 Polyhedron 16 1585

38. Declercq J P, Evrard C, Clippe A, Stricht D V, Bernard A and Knoops B 2001 J. Mol. Biol. 311751

39. Harinath Y, Reddy D H K, Kumar B N, Apparao Ch and Seshaiah K 2013 Spectrochim. Acta A 101264 